\title{
El surgimiento de nuevas islas DESINTEGRACIÓN COMERCIAL
}

\author{
Más allá de las noticias y especulaciones para los próximos años, es difícil \\ predecir las consecuencias más profundas de esta nueva situación mundial.
}

Pablo González, PhD in Economics - Texas A\&M University

Académico Facultad de Economía y Negocios UAH

a era Trump ha traído una gran cantidad de desafíos para las relaciones comerciales internacionales. Para ser justos, no es él el culpable de iniciarla precisamente, aunque quizás las decisiones adoptadas en Estados Unidos estén contribuyendo a amalgamar distintos componentes que se encuentran en la sociedad global. El Brexit fue -quizás- la primera alerta formal. La crisis del 2008/2009 reavivaron tendencias proteccionistas que parecían enterradas, y los movimientos migratorios y la xenofobia parecen haber dado lugar a una corriente hacia el aislamiento. En los últimos dos meses hemos sido espectadores de sucesivas batallas comerciales entre las grandes potencias económicas del mundo. Los primeros antecedentes se remontan a los cuestionamientos al NAFTA, al Acuerdo Transpacífico de Cooperación Económica (TPP por su sigla en inglés) y a otros acuerdos comerciales por parte de Estados Unidos. Chile mismo ha estado expectante respecto al Tratado de Libre Comercio que entró en vigor en el 2004 y que desde el 2015 permite el ingreso recíproco de productos bajo arancel cero en ambas economías. Pero lo más vívido y concreto, respecto a la tensión comercial mundial, explotó a comienzos de marzo pasado con los aranceles que impuso Estados Unidos al acero y el aluminio. Más preocupante se volvió la situación cuando, a través de excepciones otorgadas a distintos bloques comerciales y países, EEUU revela claramente que la intención es detener el comercio con China. Desde ese momento, las restricciones de uno y otro lado han ido aumentado en una especie de Guerra Fría en la cual se han cambiado la instalación de misiles con capacidad nuclear por trabas al comercio exterior. Por ahora las trabas involucran a una porción muy pequeña del comercio entre ambos países, pero dan fuertes señales. Entre las últimas noticias se sumó la posible utilización del tipo de cambio por parte de China para reimpulsar sus exportaciones.
1817. David Ricardo publica sus Principles of Political Economy, quizás uno de los tratados de economía más importantes y con mayor influencia hasta el día de hoy. Desde allí hemos aprendido que la apertura de las economías al comercio exterior es un mecanismo que permite a una sociedad alcanzar aquellos bienes para los que de una u otra forma no puede generar o no tiene las condiciones para hacerlo en forma eficiente (remarcando la importancia de las ventajas comparativas en el comercio internacional, una idea aún difícil de entender para muchos "hacedores" de políticas). Hemos aprendido que el intercambio, así como lo realizan dos particulares, permite una mejor asignación de los recursos junto a un mayor nivel de bienestar general.

No es difícil entonces comprender que esta guerra comercial que se está librando entre dos gigantes de la economía mundial, de continuar y profundizarse, va a comprometer el nivel de vida de la población, no solo de sus países sino también del resto del mundo. La producción de bienes en los lugares equivocados genera un uso ineficiente de recursos afectando cuánto podemos producir. Sin embargo, lo que es más grave aún, es que la existencia de barreras a la competencia desde el exterior puede entregar un incentivo perverso y disminuir el ritmo de avances en temas de productividad, minando las posibilidades de crecimiento hacia el futuro. El comercio internacional junto a las inversiones extranjeras directas puede resultar en un buen canal de intercambio tecnológico y aprendizaje de mejores técnicas de producción. Esa ralentización que se observa desde hace varios años en términos de crecimiento de largo plazo en los países desarrollados y que limita a su vez a los países subdesarrollados, puede aún quedar más marcada.

Pero, ¿qué podemos esperar para los años más próximos? De perdurar en el tiempo, las restricciones, la falta de competencia externa

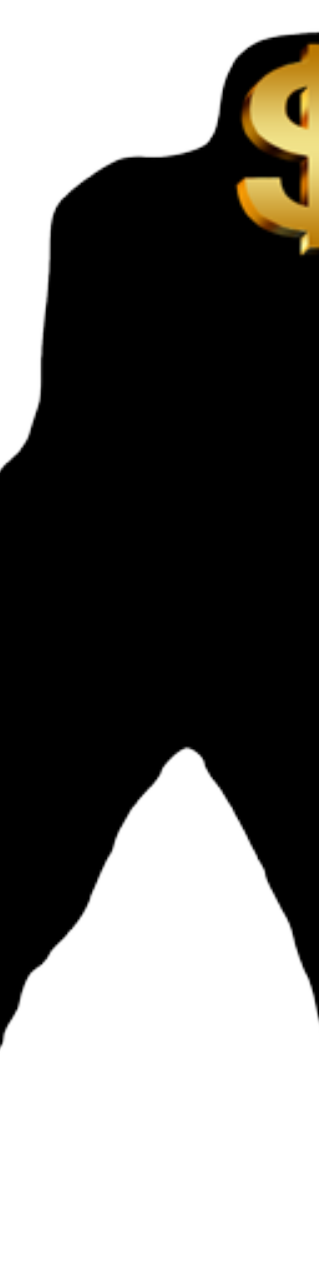

y la mala asignación de recursos llevará a presiones alcistas en los precios de los productos afectados por las nuevas restricciones a la importación. Estamos ad-portas de comenzar a transitar un periodo de suba de precios. En una visión más conceptual, este efecto sería por única vez y por lo tanto no generaría un proceso inflacionario que, desde los actores principales, se expandiera al resto del mundo. De todos modos, podría reflejarse levemente en los índices de precios, quedando en manos de los bancos centrales interpretar la persistencia de ese proceso de adaptación en los precios y la adecuación de la política monetaria eventualmente.

Para los países emergentes solo queda la observación pasiva. Es muy pronto para evaluar cuánto más chico puede resultar el mercado global y en cuánto podría verse afectado su nivel de actividad. Sin embargo, para algunos de ellos, el florecimiento de nuevas industrias en los países "beligerantes" puede abrir una nueva oportunidad de negocio, especialmente en aquellos rubros en los cuales los contendientes 


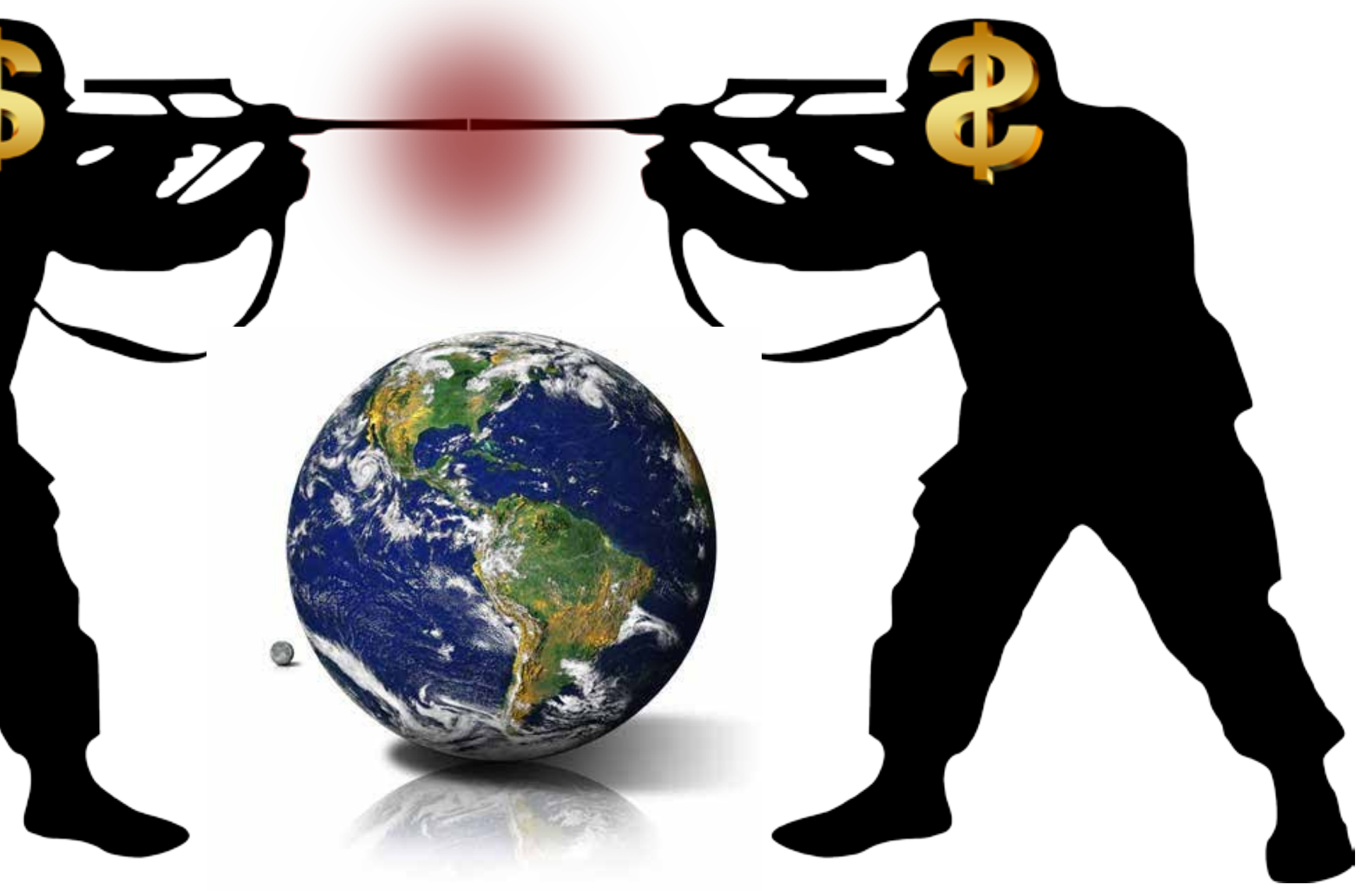

han decidido expresar sus diferencias. Lamentablemente, es grande la incertidumbre sobre cuán perdurable o transitoria esta guerra puede ser, haciendo menos atractivas y previsibles la inversión en nuevos negocios. En los mercados internacionales, aún no es clara la respuesta ante las acciones tomadas por ambas partes. Para un grupo de estos países, la situación puede llegar a ser complicada si las batallas siguen sucediéndose. Una buena porción de los países de sudeste asiático son claros proveedores a la industria china y pueden llegar a verse fuertemente afectados.

Si bien en el centro de la disputa está la visión de EEUU de corregir la balanza comercial con China con todos los instrumentos a su alcance, ya se ha manifestado la que puede ser la real causa detrás de esta historia: el espionaje industrial y la protección de los derechos de propiedad, un tema que parece va acercándose a ser resuelto bilateralmente 0 a través de la Organización Mundial de Comercio (OMC). De hecho, recientemente China ha expresado que rediseñaría sus políticas de control y protección de los derechos de propiedad, un mercado para nada insignificante.

Desde ese punto de vista, si bien la tensión actual genera algunas nubes sobre las posibilidades de crecimiento de la economía mundial,

\section{"Esta guerra comercial} que se está librando entre dos gigantes de la economía mundial, de continuar $y$ profundizarse, va a comprometer el nivel de vida de la población, no solo de sus países sino también del resto del mundo" esa mejor protección a la propiedad intelectual puede dar un nuevo impulso a la investigación y el desarrollo de nuevos procesos y productos que saquen a la humanidad de las escuálidas tasas de crecimiento tendencial.

Por lo pronto, si el conflicto escala, las posibilidades de transformar esta batalla comercial en una cambiaria (como lo amenazó China) a través de devaluaciones competitivas podría poner en vilo a un sistema y políticas monetarios que se han acostumbrado a bajas tasas de inflación.

Por lo pronto, para Chile, solo queda estar expectante, aunque debemos reconocer la poca capacidad para influir en este contexto o incluso prepararnos preventivamente. El conflicto afecta no solo a China (un gran socio comercial) y EEUU (que si bien ha perdido peso en nuestro comercio sigue siendo importante), sino que indirectamente a un sudeste asiático que hace exactamente 20 años nos puso en unas de las crisis económicas más complicadas y duradera de la historia reciente. Mientras tanto, aventurar números parece un ejercicio difícil y casi sin sentido. Estamos frente a una experiencia en la economía internacional complicada de dimensionar. $\mathbf{E}$ 